\title{
ARE STUDENTS SATISFIED WITH THE USE OF SMARTPHONE APPS?
}

\author{
Sun Gi Chun, Alabama State University, sungichun@alasu.edu \\ Dalsang Chung, Governors State University,dchung@govst.edu \\ Yong B. Shin, Francis Marion University, YShin@fmarion.edu
}

\begin{abstract}
No matter what smartphone you use, applications (apps) installed can affect your satisfaction with the use of the smartphone. A smartphone is a consumer device, and smartphone apps are Consumer Information Systems (CIS) that provide value and utility to end-users. Major players in the area of smartphone apps are developers creating apps as well as consumers downloading and using apps. The research focuses on consumer aspects of smartphone apps in terms of their satisfaction with the use of the apps. The study elaborates on factors affecting consumers' satisfaction such as needs fulfillment, performance improvement, easy to use, easy to understand, security/privacy, and influence of the peer. The study also finds out who are satisfied with smartphone apps in terms of age, gender, frequent user, years of usage, and preference for free apps. A survey was conducted to college students representing consumers. In the study, most respondents were satisfied with the use of smartphone apps, and their satisfaction level was affected by factors such as needs fulfillment, performance improvement, ease of use, security/privacy, and peer influence. It is also found out that consumers of younger age, frequent users, frequent downloaders, having more number of apps on their smartphones, and choosing Android and iOS as their future smartphone platforms were more satisfied while gender, longer years of owning smartphone, preference for free apps, and smartphone platforms currently used did not significantly affect consumers' satisfaction.
\end{abstract}

Keywords: Smartphone, Apps, Satisfaction, and Usage.

\section{INTRODUCTION}

Advanced mobile devices, such as smartphones and personal digital assistants, have become ubiquitously available and have changed the ways how people organize relationships, communicate, and live on a daily basis. Because users carry mobile devices everywhere and all the time, the devices have become one of the most important personal information-processing interfaces. Users realize the increasing value of smartphone devices, and swiftly change and upgrade to innovative brands with cutting-edge features getting easily access to available applications (apps). In today's global market, smartphone apps have become the mainstream of consumer's daily lives as the smartphone has turned out to be a major segment in the mobile phone market [17].

The American Dialect Society voted "app" as the word of the year for 2010. An app is defined as a software program for a computer or phone operating system. It is also called mobile apps, that is, a term used to describe Internet applications that run on smartphones and other mobile devices. With the arrival of app stores for a wide spectrum of operating systems for smartphones, tablets, and computers, the app has certainly exploded in popularity [16].

Apple's iPhone and App Store have amazingly demonstrated business success and technological innovation, which are motivating Information Systems researchers to shift the focus of research from app design and development to the understanding of consumers as end-users of mobile services and applications [19]. Consumer oriented research focuses on value, and what utility end-users receive would be closely related to the improvement of the development and design of mobile services and apps.

The objective of the paper is to study users' satisfaction with smartphone apps. In order to find out consumers' satisfaction with the use of smartphone apps, a survey was conducted. The study also discovered groups who are satisfied with smartphone apps in terms of age, gender, frequent user, years of usage, and preferred apps. 


\section{LITERATURE REVIEW}

Smartphone apps are considered as consumer information systems (CIS). CIS are information systems (IS) which provide services primarily to consumers instead of addressing needs of users in the traditional organizational setting. According to Tuunanen [19], CIS is an emerging area that brings up interesting problems. For example, traditional IS development approaches focus on improving the efficiency and effectiveness of organizational processes, whereas the design of CIS may emphasize hedonic value derived from experiences of consumers. For example, smartphone users are pleased when they use a travel app to plan a vacation. The shift of focus from users to consumers calls for a significant re-appraisal of the current IS development methods and the ways mobile services and applications are designed. More study on the connection between mobile apps/services and the value and utility provided to end-users is needed. Therefore, CIS opens up interesting avenues for research on system and service quality, since both consumers and developers are incorporated as active participants in the value creation process [20].

Smartphone apps are developed by individuals, businesses, government agencies, the military, educational institutions, and any other organizations that want to use the technology to entertain, solve a problem, and fulfill a need. According to a mobile application report made by Mobile Marketing Association, the main types of communication apps are e-mail clients, instant messaging clients, mobile web browsers, news clients, and social network clients [11]. Consumers also enjoy various games like puzzles, cards, action/adventure, sports, and leisure sports while multimedia apps help consumers view vivid graphics/images, audio, video, and streaming contents. Some productivity apps include calendar, calculator, note/memo, spreadsheet, directory, and banking/finance apps.

In the past few years, brick-and-mortar companies as well as mobile companies have spent millions of dollars attracting app developers. In the mobile app market, there are more than one million app developers of diverse shapes and sizes. Because app developers are often unable to predict the actual use of developed apps, it is important for app developers to know what value end-users may place on the apps and understand how they might be used. Text messaging is a good example. A Finnish engineer who originally developed text messaging thought the technology to be useful only for messaging among base stations of cell towers. The vision of the engineer at that time was very limited because he did not even daydream that billions of text messages would be sent every day. Therefore, developers must examine the context in the use of their apps, and develop apps to meet consumers' needs, whether consumers are interacting with each other, buying bus and train tickets, paying for parking, or ordering information services such as weather reports [20].

A report was made by Intel [9] to inform app developers of creative, commercial, and technical tips on how to be profitable. The tips answer a relevant question, "What makes a good app?" The answer was focused on adding value and utility to users. The tips are briefly introduced as follows: 1) A good app fulfils a need. It is not valuable if developers design elegant apps that nobody wants to use. For a game app, the need is entertainment while for a productivity app, the need is to help people achieve work goals. 2) A good app is effective. The app should do well whatever it sets out to do. People are more likely to shop around for an alternative app than tolerate one that falls short of their expectation. 3) A good app looks attractive. Whether it is a game or a utility, the app needs to look good. The first impression counts. People will judge the quality of apps at the initial presentation of apps. 4) A good app is focused. While most software on our desktop computers can do many functions with various features we have never used, the most successful apps focus on one particular goal. App users prefer simplicity. 5) A good app is intuitive. People don't read a user manual to get apps started. They expect app interface to be easy to use so that they can get started with minimal guidance. An app of familiar icons, conventions, and operating systems will be easily adopted.

App developers must take numerous success factors into consideration when developing an app. Hyatt [8] includes factors such as pricing and promoting apps strategically with the price of free, 99 cents, or $\$ 5.99$, and developing apps for multiple platforms to accommodate larger numbers of smartphones. Furthermore, Balakrishnan [3] explains how apps are used to make target customers smarter, which is an important factor to consider as app developers. He also discusses that apps would provide consumers, particularly those with low technological skill, with useful information and value added services in an easy-to-use manner.

Wireless carriers are also considered an important factor of consumers' satisfaction with smartphone apps because they place limits on data usage on the smartphone. In the Raphael report [14], all except one of the major U.S. wireless carriers restricts data usage on the smartphone. AT\&T and Verizon charge if consumers go over the allotted number of bytes, while T-Mobile 
slows transmission speed down to a crawl for those who have exceeded their assigned data limit. Only Sprint continues to offer unlimited data plans to consumers.

Privacy and security of apps are important issues for smartphone users. According to Chung \& Chun [4], security is one of the important factors determining smartphone selection. They explain that a large amount of personal data is stored on smartphones, and that this data can be compromised by losing a phone or by being infected by malicious software. They also explain that apps can compromise consumer privacy. According to Consumer Report [2], more than 8 million people in the world use Foursquare, a social network app that lets users comment about restaurants and stores with incentives of discounts and free gifts. However, the service can let friends and strangers on social networking sites know locations of the users through the GPS tracking features of smartphones.

Legislators are more aware of privacy issues on smartphone apps. Paoli [12] discussed a press release by San Francisco Attorney General Kamala D. Harris on February 22, 2012, where she announced an agreement with the leading mobile app platforms to improve privacy protections for millions of consumers in the world. The accord, signed by Microsoft, Amazon, Apple, Google, Research in Motion, and Hewlett-Packard, mandates that mobile apps downloaded must provide detailed information on what personal data will be collected, and how it will be used. The agreement will allow consumers a chance to review an app's privacy policy before they download the app rather than after, and will consistently inform consumers of the location of privacy policy on the app's downloading screen. If app developers do not comply with the stated privacy policies, they can be prosecuted under California's Unfair Competition Law and False Advertising Law.

Apple and Android, as the major smartphone platforms, are also concerned about privacy and security related to Smartphone apps. On July 31, 2009, the Federal Communications Commission (FCC) sent Apple, Google, and AT\&T letters of inquiry relating to an incident where Apple allegedly rejected an application that Google submitted for approval to Apple's application marketplace called App Store. Google submitted the application to the App Store that would allow Apple's iPhone to use features of Google Voice. In its response to the FCC, Apple claimed that it rejected the application for various software quality problems. In the case of the rejection of an application, Apple should specifically guide the developer to fix problems in the apps and resubmit the application. Apple rejects an application if it "degrades the core experience of the iPhone." Examples of such degrading applications include those that may contain explicit content, compromise consumer privacy, expose children to inappropriate content, contain malicious or harmful software components, or include pornographic content. Apple states that it provides guidelines to app developers in the developer agreement. It claims that a team of trained professionals reviewed applications uniformly [5].

According to Phifer [13], Android malware has surged because malware authors take advantage of Google's open Android market, and Android is willing to load apps from third-party sites. According to Tu [18], based on comScore report as of December 2012, top smartphone platforms were Google (53.4\%), Apple (36.3\%), Blackberry (6.4\%), Microsoft (2.9\%), and Symbian (0.6\%). In other words, consumers purchase Android smartphones 1.5 times the number of Apple iPhones. As a result, employers consider what is a secure smartphone OS for business when they choose the device. Mobile device management (MDM) agents or other security programs installed on the smartphone are used as protection from malware. MDM downloaded from Android market is used to authenticate the user, issue a device certificate, and enforce the organization's policies. Although Android focuses on securing enterprise data breaches, Android app developers need to consider consumer data breaches affecting privacy and security.

Grace, Zhou, Jiang and Sadeghi [7], also discussed the app market. They reported that for the past couple of years, smartphone sales have grown explosively. According to Gartner, smartphones outsold personal computers for the first time in history. Evidently, consumers embraced smartphones due to their convenience and power, because customers can download plenty of third-party apps that provide additional useful features. Furthermore, Google and Apple as platform vendors also provide centralized app markets where users can simply browse, search, purchase, download, and install apps.

Doidge [6] reported that market for mobile apps would be very competitive, especially for the integration of innovative apps and platform layer technology. In 2012, end-users were expected to spend $\$ 15.9$ billion on mobile apps, which would drive supplementary hardware sales, advertising spending, and further technological innovation. The author also reported that Gartner expected brand companies to increasingly shift their marketing budget to the mobile channel, and experiment with cutting-edge apps to capture marketing and sales opportunities. Ten (10) consumer mobile apps were identified in the watchable list by Gartner, which were location-based services, social networking, mobile search, M-commerce, M-payments, context-aware services, object recognition, mobile instant messaging, mobile email, and mobile video. 
Smartphone devices and apps are powerful tools that companies can harness to engage customers, serve partners, and empower employees. Even though smartphones are smaller, faster, and cheaper devices running tiny web or screen-scraped apps, smartphones brings a much more holistic and far-reaching change to customers' lives. Apps are in the customer's pocket. Forrester [15] believes that mobile apps are the forefront of new systems of engagement that empower customers, employees, and partners to help them decide and act immediately in their moments of need.

comScore [1] presented its annual report examining the mobile and connected device landscape over eight markets: United States, Japan, United Kingdom, Canada, Spain, France, Italy, and Germany. The report explored some of the key trends driving smartphone adoption growth and found that apps were one of the critical components of adoption. Smartphone owners rated the selection of apps and music/video capabilities as significantly important aspects in their purchasing decision. The report explained that the strong growth in the usage of apps would reach parity with the mobile browsers. In December 2011, 47.6 percent of the total mobile audience in the U.S used apps with an increase of $13.3 \%$ while 47.5 percent used mobile browsers.

It is believed that when consumers make a selection decision on smartphone devices and apps, preferences of the peer are influential. Social Influence Network Theory (SINT) is a combination of social network theory and social diffusion theory. According to Johnsen and Friedkin [10], social diffusion is a process by which particular thoughts (attitudes, opinions, or beliefs), feelings (emotions, sentiments, or moods), or behaviors (decisions, actions, or practices) are spread among members of a social network. This theory suggests that for consumers' adoption of smartphone devices and apps, they are more likely to select the smartphone and apps that are most popular within the particular social network. However, it is expected that this causal relationship will diminish as the user develops experience with various smartphone platforms and accordingly is able to critically evaluate core competencies of the device based on user's core requirements being independent of the social network. Finally, it is further expected that this causal relationship will diminish as the user's age increases.

\title{
Research Questions
}

\section{THE OBJECTIVE OF THE STUDY IS TO FIND OUT CONSUMERS' SATISFACTION WITH THE USE OF SMARTPHONE APPS. THE RESEARCH QUESTIONS ARE AS FOLLOWS:}

1. ARE CONSUMERS SATISFIED WITH THE USE OF SMARTPHONE APPS?

2. WHAT FACTORS AFFECT CONSUMERS' SATISFACTION OF SMARTPHONE APPS?

\author{
3. WHO ARE THE SATISFIED CONSUMERS IN TERMS OF AGE, GENDER, LENGTH OF USE, AND \\ FREQUENCY OF USE?
}

\section{BASED ON LITERATURE, FACTORS AFFECTING CONSUMERS' SATISFACTION WITH SMARTPHONE APPS ARE FULFILLMENT OF NEEDS, PRODUCTIVITY TOOLS, WORK PERFORMANCE IMPROVEMENT, USER FRIENDLY AND EASY TO USE INTERFACE, SECURITY/PRIVACY, AND PREFERENCE OF THE PEER.}

In terms of demographics of consumers, it is expected that younger consumers would be more satisfied with the use of smartphone apps and gender does not make any difference. It is expected that consumers with the experience of the longer and more frequent use of smartphone apps would be more satisfied.

\section{RESEARCH METHODOLOGY}

The survey instrument was designed to have twelve (12) items to measure four (4) major factors, that is, perceived usefulness, perceived ease of use, consumers' security/privacy concern, and social peer's influence. Nine (9) items to measure consumers' perception of major satisfaction factors were statements for respondents to reply on a 5-point Likert scale, that is, one (1) for strongly disagree and five (5) for strongly agree. Three (3) items were designed separately to examine social peer's influence by five (5) degrees of social conformity in terms of smartphone devices, apps, and wireless carriers, (1) for none, and (5) for most. Four (4) levels of consumers' satisfaction with smartphone apps, (1) for very low to (4) for very high were asked to users of smartphone apps. Questions on demographics of subjects were included in the 


\section{Issues in Information Systems}

Volume 14, Issue 2, pp.23-33, 2013

survey such as age and gender. Also, items on consumers' personal experience with smartphone owning, frequent usage, download of apps, number of apps, and preference of free apps.

The target population for the survey was college students in Midwestern states who possessed smartphones and used smartphone apps. Individual respondents were solicited through a survey. Variables involved in this survey were the degree of consumers' satisfaction with smartphone apps as a dependent variable, and perceived usefulness, ease of use, security/privacy, and social conformity as independent variables. Factor analysis was applied to find out relevant factors for consumers' satisfaction with smartphone apps. Chi-Square tests were employed to test the consumers' demographic and research questions.

\section{RESULTS}

Two hundred (200) usable responses were received with 55\% from females and 45\% from males (Table 1). 55\% of the respondents were $20-35$ years of age, $32 \%$ were $36-50$, and $13 \%$ were aged 51 or over. Focusing on actual users of smartphones, 165 out of 200 actually possessed smartphone devices and used smartphone apps.

Table 1. Demographics of Respondents

\begin{tabular}{|c|c|c|c|c|c|c|c|c|}
\hline & \multicolumn{5}{|c|}{ AGE } & \multicolumn{3}{|c|}{ GENDER } \\
\hline & Under 20 & 20-35 & $36-50$ & $\begin{array}{l}51 \text { OR } \\
\text { OVER }\end{array}$ & TOTAL & MALE & FEMALE & TOTAL \\
\hline USER & $\begin{array}{c}1 \\
(1 \%)\end{array}$ & $\begin{array}{c}93 \\
(47 \%)\end{array}$ & $\begin{array}{c}55 \\
(28 \%)\end{array}$ & $\begin{array}{c}14 \\
(7 \%)\end{array}$ & $\begin{array}{c}163 \\
(82 \%)\end{array}$ & $\begin{array}{c}77 \\
(39 \%)\end{array}$ & $\begin{array}{c}86 \\
(43 \%)\end{array}$ & $\begin{array}{c}163 \\
(82 \%)\end{array}$ \\
\hline NON-USER & $\begin{array}{c}0 \\
(0 \%)\end{array}$ & $\begin{array}{c}16 \\
(8 \%)\end{array}$ & $\begin{array}{c}9 \\
(5 \%)\end{array}$ & $\begin{array}{c}10 \\
(5 \%)\end{array}$ & $\begin{array}{c}35 \\
(18 \%)\end{array}$ & $\begin{array}{c}14 \\
(7 \%)\end{array}$ & $\begin{array}{c}21 \\
(11 \%)\end{array}$ & $\begin{array}{c}35 \\
(18 \%)\end{array}$ \\
\hline TOTAL & $\begin{array}{c}1 \\
(1 \%)\end{array}$ & $\begin{array}{c}109 \\
(55 \%)\end{array}$ & $\begin{array}{c}64 \\
(32 \%)\end{array}$ & $\begin{array}{c}24 \\
(12 \%)\end{array}$ & $\begin{array}{c}198 \\
(100 \%)\end{array}$ & $\begin{array}{c}91 \\
(46 \%)\end{array}$ & $\begin{array}{r}107 \\
(54 \%)\end{array}$ & $\begin{array}{c}198 \\
(100 \%)\end{array}$ \\
\hline
\end{tabular}

Out of 165 users, 93 (57\%) belonged to the age group of 20-35, and 55 (34\%) were in the age group of $36-50$ while 14 (8\%) were in the age group of 51 or over, and 1 (1\%) was in the age group of under 20 (Figure 1). Out of 165 users, 77 (47\%) were males and $86(53 \%)$ were females.

In terms of years of owning smartphones and using apps, $46(28 \%)$ users belonged to a group of more than 2 years of usage while $66(40 \%)$ users have used between 1 and 2 years, and $53(32 \%)$ were in the group of less than 1 year. In terms of the frequent usage of apps, 91 (56\%) users said 'very often', and 39 (24\%) said 'often' while 19 (12\%) said 'sometimes', 13 $(8 \%)$ answered 'rarely', and $1(0 \%)$ did 'never'.

$152(94 \%)$ out of 162 respondents were satisfied with the use of smartphone apps while 10 were not satisfied. 137 out of 165 users most frequently got access to email apps, and 103 did social networking apps as the second most used apps. The next 


\section{Issues in Information Systems}

Volume 14, Issue 2, pp.23-33, 2013

frequently used apps were mapping and direction (98), instant messaging (91), weather/travel (87), music/radio (86), game (73), business productivity (30), e-commerce (21), and relationship promoting apps (10). The frequency of consumers' downloading apps were never (9\%), rarely (23\%), sometimes (34\%), frequently (26\%), and very frequently $(8 \%)$. $43 \%$ of respondents downloaded as many as $0-10$ apps while $22 \%$ downloaded more than 20 apps. Users preferred free (89\%) smartphone apps to paid ones.

Out of the respondents, $54 \%$ of their smartphones ran on the Android platform while $33 \%$ did on iOS, that is, iPhone platform. However, when asked which phone they would buy a next, $43 \%$ of respondents, which is $10 \%$ more preferred to an iPhone, while as $42 \%$ of respondents, which is $12 \%$ less chose Android.

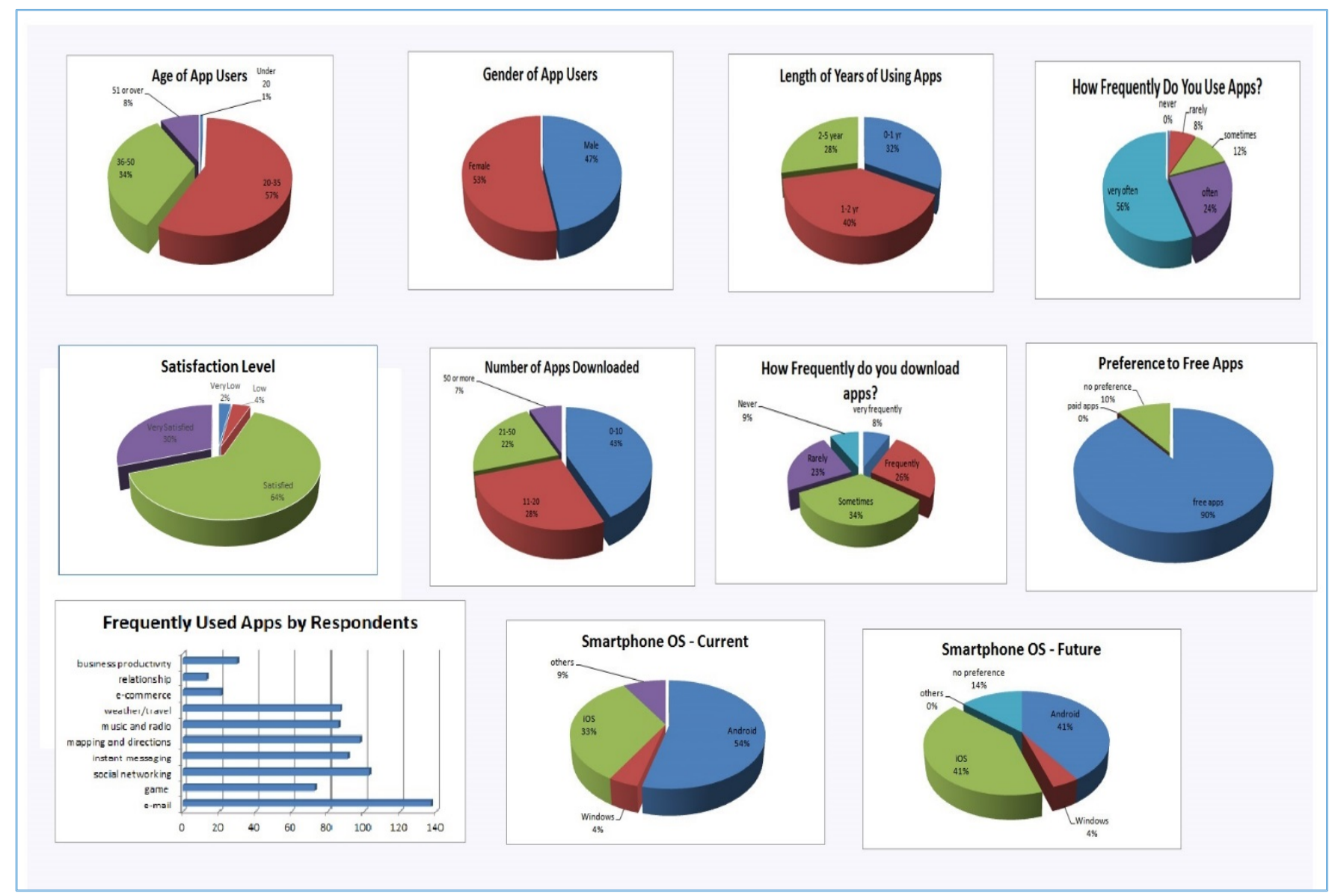

Figure 1. Demographics on Smartphone App Users and Their Personal Usage Experience and Preference

In terms of perceived usefulness, $65 \%$ of respondents agreed that they used the apps usefully in their daily lives, which was important to accomplish their daily needs. However, using these apps to perform tasks for the job is another matter. Only $39 \%$ of respondents agreed that using an app has increased productivity on the job, and 34\% of respondents agreed that using an app has improved job performance. On a personal level, 55\% of respondents agreed that using apps was helpful to get work done. In terms of ease of use, $84 \%$ of respondents agreed that these apps were easy to operate while $79 \%$ agreed that the apps were clear and understandable. 


\section{Issues in Information Systems}

Volume 14, Issue 2, pp.23-33, 2013

Security has become a major concern in the mobile world because it is just as easy to compromise a smartphone as it is a PC. $65 \%$ of respondents were concerned about security issues of their phones, and $63 \%$ were concerned about their personal information being disclosed when downloading apps. $69 \%$ of respondents observed the privacy rules set in the smartphone operating system. In terms of social conforming, $40 \%$ of respondents agreed that the peer chose the same smartphone. $45 \%$ of respondent agreed that the peer used/owned the same apps, and $34 \%$ of respondents agreed that the peer used the same carrier.

As shown in the Table 2, 10 out of 12 instrument measurement items were grouped into 4 factors as a result of factor analysis with Varimax rotation method. Thus, remaining factors were perceived usefulness, ease of use, security/privacy, and social conforming. Out of the security/privacy factor, an item, consumers' observance of the privacy rules set on the smart phone operating system was not significant. Out of the social conforming factor, an item, preference of peer group for choosing smartphones was not significant. Thus, the two items were dropped from further analysis. The respondents conformed significantly to their peers' opinion on apps as well as wireless carrier, while they did not conform to the peer's opinion on smartphone selection. 


\section{Issues in Information Systems}

Volume 14, Issue 2, pp.23-33, 2013

Table 2. Result of Factor Analysis

\begin{tabular}{|l|l|l|}
\hline Factors & Measurement Items & Factor Loading \\
\hline \multirow{4}{*}{ Usefulness } & Using an app has enabled you to accomplish your need (NEFL)* & $\mathbf{0 . 6 5 0 2 9}$ \\
\cline { 2 - 3 } & Using an app has increased productivity on the job (PRIN)* & $\mathbf{0 . 8 1 6 0 4}$ \\
\cline { 2 - 3 } & Using an app has improved your job performance (JBPR)* & \\
\cline { 2 - 3 } & Get the work done through apps (WKDN)* & $\mathbf{0 . 8 4 7 8 9}$ \\
\hline \multirow{5}{*}{ Security/Privacy to Use } & Apps are easy to operate (EASY)* & $\mathbf{0 . 6 3 4 2 7}$ \\
\cline { 2 - 3 } & Interaction with an apps is clear and understandable (UNDR)* & $\mathbf{0 . 8 7 3 3 1}$ \\
\cline { 2 - 3 } & I am concerned about the security issues of phone (SECU)* & $\mathbf{0 . 7 8 4 7 1}$ \\
\cline { 2 - 3 } & $\begin{array}{l}\text { I always observe the privacy rules set in the smart phone operating system } \\
\text { (PROS) }\end{array}$ & $\mathbf{0 . 7 3 3 0 8}$ \\
\hline \multirow{5}{*}{$\begin{array}{l}\text { Social } \\
\text { Conforming }\end{array}$} & Your peer own/use the same apps (NPEA)* & $\mathbf{0 . 6 0 3 3 1}$ \\
\cline { 2 - 3 } & Your peer use the same carrier (NPEC)* & $\mathbf{0 . 5 7 2 3 2}$ \\
\cline { 2 - 3 } & Your peer choose the same smartphones (PEEP) & NS \\
\hline
\end{tabular}

Note: * indicates variables are significant with factor loadings.

Multiple discriminant analysis was conducted to find out what factors influenced the respondents' satisfaction. After the factor analysis, 10 variables as independent variables and 4 satisfaction levels as dependent variable were used to conduct multiple discriminant analysis. As shown in the Table 3, Wilks' Lambda was 0.5925 and p-value was 0.0008 , which was significant because $\mathrm{p}$-value was less than the significant level of 0.05 . Therefore, the 10 variables can significantly explain the variance of respondents' satisfaction levels.

Table 3. Canonical Discriminant Analysis

\begin{tabular}{|l|l|l|l|l|l|}
\hline Statistic & Value & F-Value & Numerator DF & Denominator DF & Pr $>$ F \\
\hline Wilks' Lambda & 0.5925 & 2.05 & 33 & 348.35 & 0.0008 \\
\hline EigenValue - Can1 & 0.3209 & 2.05 & 33 & 348.35 & 0.0008 \\
\hline EigenValue - Can2 & 0.2290 & 1.55 & 20 & 238 & 0.0660 \\
\hline EigenValue - Can3 & 0.0396 & 0.53 & 9 & 120 & 0.8516 \\
\hline
\end{tabular}

As shown in the Table 4, two variables in the useful factor, NEFL and PRIN were significant to predict respondents' satisfaction level while JBPR and WKDN were not significant. Two variables in the ease of use factor, EASY and UNDR were significant. Two variables in the security/privacy factor, SECU and PEIN were significant. One variable in the social conforming factor, NPEA was significant while NPEC was not significant. Particularly, ease of use factor for app design was very significant to satisfy respondents. 


\section{Issues in Information Systems}

Volume 14, Issue 2, pp.23-33, 2013

Table 4. Standardized Canonical Structure, R-Square, and Probability

\begin{tabular}{|l|l|r|r|r|r|r|r|}
\hline \multirow{3}{*}{ Factors } & \multirow{3}{*}{ Variables } & \multicolumn{3}{|c|}{ Multivariate } & \multicolumn{3}{c|}{ Univariate } \\
& & \multicolumn{3}{|c|}{ Analysis } & \multicolumn{3}{c|}{ Analysis } \\
\cline { 3 - 8 } & & \multicolumn{1}{|c|}{ Can1 } & \multicolumn{1}{c|}{ Can2 } & \multicolumn{1}{c|}{ Can3 } & R-Square & F-Value & \multicolumn{1}{c|}{ Pr>F } \\
\hline \multirow{3}{*}{ Usefulness } & . NEFL & 0.565 & -0.081 & -0.023 & 0.0856 & 3.65 & $0.0144^{*}$ \\
& . PRIN & 0.379 & -0.367 & 0.158 & 0.0649 & 2.77 & $0.0443^{*}$ \\
& . JBPR & 0.237 & -0.203 & -0.015 & 0.0219 & 0.93 & 0.4270 \\
& . WKDN & 0.395 & 0.094 & 0.237 & 0.0434 & 1.85 & 0.1408 \\
\hline Easy to Use & . EASY & 0.816 & -0.008 & -0.166 & 0.1944 & 8.29 & $<.0001^{*}$ \\
& . UNDR & 0.833 & 0.186 & -0.021 & 0.2124 & 9.06 & $<.0001^{*}$ \\
\hline Security/Privacy & . SECU & -0.259 & 0.747 & 0.195 & 0.1384 & 5.90 & $0.0008^{*}$ \\
& . PEIN & -0.388 & 0.347 & 0.409 & 0.0699 & 2.98 & $0.0339^{*}$ \\
\hline Social & . NPEA & 0.622 & 0.012 & 0.360 & 0.1097 & 4.68 & $0.0039^{*}$ \\
Conforming & . NPEC & 0.371 & -0.106 & 0.525 & 0.0483 & 2.06 & 0.1086 \\
\hline
\end{tabular}

Note: * indicates that variables are significant at 0.05 level.

As shown in the Table 5, multiple discriminant analysis was conducted to find out who are satisfied with the use of smartphone apps. Age, frequent usage, frequent download of apps, number of apps downloaded, and future platforms were significant for respondents' satisfaction while gender, years of owning the smartphone, preference to free apps, and current smartphone platforms were not significant for respondents' satisfaction. In terms of age, respondents between the age of 20 and 35 were more satisfied with the use of apps while those of age above 35 were mostly satisfied. Frequent users of apps were more satisfied with apps, and users downloading apps frequently were more satisfied. Users downloading more apps were satisfied with their use of apps. Most respondents said they preferred free apps while few said they did not have any preference for free or paid apps. User's preference for free apps was not significant for their satisfaction. In terms of current platform of smartphone, most respondents using Android and iOS were more satisfied than with other platforms, but the current OS as variable was not significant. In terms of future platform for the new smartphone they want to own in the near future, respondents still preferred Android and iOS platforms while 22 respondents said they did not have any preference for smartphone platforms. The future platform of smartphone apps was significant for respondents' satisfaction.

Table 5. Canonical Discriminant Analysis between Satisfaction Levels and Demographics of Users, and Usage of Apps

\begin{tabular}{|l|l|l|l|l|l|l|l|l|l|}
\hline & Age & Gender & $\begin{array}{l}\text { Years of } \\
\text { Owning }\end{array}$ & $\begin{array}{l}\text { Frequency } \\
\text { of Use }\end{array}$ & $\begin{array}{l}\text { Frequency } \\
\text { of } \\
\text { Download } \\
\text { Apps }\end{array}$ & $\begin{array}{l}\text { Number of } \\
\text { apps } \\
\text { downloaded }\end{array}$ & $\begin{array}{l}\text { Free or } \\
\text { Pay } \\
\text { Preference }\end{array}$ & $\begin{array}{l}\text { Platform- } \\
\text { Current }\end{array}$ & $\begin{array}{l}\text { Platform- } \\
\text { Future }\end{array}$ \\
\hline Satisfaction & $\mathbf{P}=\mathbf{0 . 0 0 0 2 *}$ & $\mathrm{P}=0.7522$ & $\mathrm{P}=0.9553$ & $\mathbf{P}<\mathbf{0 . 0 0 0 1 *}$ & $\mathbf{P}=\mathbf{0 . 0 0 0 4} *$ & $\mathbf{P}=\mathbf{0 . 0 0 6 6} *$ & $\mathrm{P}=0.6200$ & $\mathrm{P}=0.0921$ & $\mathbf{P}=\mathbf{0 . 0 1 3 9 *}$ \\
\hline
\end{tabular}

Note: * indicates that variables are significant at 0.05 level. 


\section{Issues in Information Systems}

Volume 14, Issue 2, pp.23-33, 2013

\section{CONCLUSIONS}

No matter what smartphone you use, apps installed can affect your satisfaction with the use of the smartphone. The study focuses on consumer aspects of smartphone apps in terms of their satisfaction with the use of the apps. In the study, most respondents were satisfied with the use of smartphone apps. Consumers' satisfaction was affected by factors such as needs fulfillment, performance improvement, ease of use, security/privacy, and influence of the peer. It was also discovered that consumers of younger age, frequent users, frequent downloaders, having more number of apps on their smartphones, and preferring Android and iOS as their next smartphone platforms were more satisfied while gender, longer years of owning smartphone, preference for free apps, and smartphone platforms currently used did not significantly affect consumers' satisfaction.

The limitation of the study was that the number of smartphone app end-users was relatively small. That is, 165 were employed to conduct multiple discriminant analysis among satisfaction levels, factor variables, and demographic categories of respondents. Moreover, the ratio of the young age group below 20 years old out of respondents was only $1 \%$ of the respondents, therefore, the relationship between satisfaction level and age group was not fully examined in the study.

\section{REFERENCES}

1. “2012 U.S. Digital Future in Focus.” (2012). Retrieved from comScore: http://www.comscore.com/Press_Events/Presentations_Whitepapers/2012/2012_US_Digital_Future_in_Focus

2. “Online Exposure" (2011). Consumer Reports, 76(6), 29-31.

3. Balakrishnan, R. (2011). Apps Developer: Deveoping Apps is About Making a Section of the Target Audience Smarter. Retrieved from The Economic Times (Online): http://articles.economictimes.indiatimes.com/2011-1230/news/30569390_1 app-developers-nokia-life-tools-jawahar-kanjilal

4. Chung, D., \& Chun, S. (2011). An Exploratory Study on Determining Factors for the smartphone Selection Decision. Issues in Information Systems, 12(1), 291-300. Available: http://www.iacis.org/conference/proceedings/IACIS_2011_Proceedings.pdf

5. Croft, J. (2010) Mobile Computing: Why You May Never See Some Great Apps. Retrieved from Social Science Research Network: http://papers.ssrn.com/sol3/papers.cfm?abstract id=1601089

6. Doidge, F. (2011) Market on the Move. Retrieved from Computer Reseller News: ABI/INFORM Global. (Document ID: 2392783161). http://proquest.umi.com/pqdweb?did=2392783161\&sid $=2 \& \mathrm{Fmt}=6 \&$ clientId $=8447 \& \mathrm{RQT}=309 \& \mathrm{VName}=\mathrm{PQD}$

7. Grace, M., Zhou, W., Jiang, X., \& Sadeghi, A. (2012). Unsafe Exposure Analysis of Mobile In-App Advertisements. Retrieved from Department of Computer Science, North Carolina State University: http://www.csc.ncsu.edu/faculty/jiang/pubs/WISEC12_ADRISK.pdf

8. Hyatt, J. (2010). How to Buid a Better App. Newsweek, 156(12), 44.

9. Intel. (2012). How to Create Your Own Apps Business. Retrieved from Mobile Entertainment: The Business of Mobile Content: http://www.mobile-ent.biz/reports/read/how-to-create-your-own-apps-busi

10. Johnsen, E., \& Friedkin, N. (2006). Social Influence Network Theory: Diffusion of Attitudes leading to Behavior. Paper presented at the annual meeting of the American Sociological Association, Montreal Convention Center, Montreal, Quebec, Canada. Retrieved from http://citation.allacademic.com//meta/p_mla_apa_research_citation/1/0/5/1/1/pages105115/p105115-1.php

11. Mobile Marketing Association (2008). Mobile Applications. Retrieved from http://www.mmaglobal.com/mobileapplications.pdf

12. Paoli, C. (2012). Google, Microsoft, \& Apple Agree on Mobile Privacy Accord. Retrieved from Application Development Trends: http://adtmag.com/articles/2012/02/23/mobile-privacy-accord.aspx

13. Phifer, L. (n.d.). Android Security Settings and Controls for Android Enterprise Security. Retrieved from SearchSecurity.com: http://searchsecurity.techtarget.com/tip/Android-security-settings-and-controls-for-Androidenterprise-security 


\section{Issues in Information Systems}

Volume 14, Issue 2, pp.23-33, 2013

14. Raphael, J. (2012). Smart Phone Data Shake-Up: The End of 'Unlimited'. Retrieved from ComputerWorld: http://www.computerworld.com/s/article/9223891/Smartphone_data_shake_up_The_end_of_unlimited_?taxonomyI $\mathrm{d}=15$ \&pageNumber=1App $\% 20$ privacy $\% 20$

15. Schadler, T., \& McCarthy, J. (2012). Mobile is the New Face of Engagement. Retrieved from Forrester Research: http://cdn.blog-sap.com/innovation/files/2012/08/SAP Mobile Is The New Face Of Engagement.pdf

16. Society, A. D. (2011). "App" Voted 2010 Word of the Year by the American Dialect Society. Retrieved from American Dialect Society: http://www.americandialect.org/app-voted-2010-word-of-the-year-by-the-americandialect-society-updated

17. Tscherning, H., \& Mathiassen, L. (2010). Early Adoption of Mobile Devices: A Social Network Perspective, Journal of Information Technology Theory Application, 11(1), 23-42.

18. Tu, J. (2013). comScore: Despite Windows Phone 8, Microsoft's U.S. smartphone share continues decline. Retrieved from the Seattle Times:

http://seattletimes.com/html/microsoftpri0/2020302662_despite_windows_phone_8_microsofts_us_smartphone_s.ht ml?syndication $=$ rss

19. Tuunanen, T. (2010). Editorial: Value of Mobile Applications and Services. Journal of Information Technology Theory and Application, 11(1), 1-4.

20. Tuunanen, T., Myers, M. D., \& Cassab, H. (2010). A Conceptual Framework for Consumer Information Systems Deveopment. Pacific Asia Journal of the Association for Information System, 2(1), 46-66. 